Research Article

\title{
Preparation and characterization of floating tablet of Losartan Potassium for gastric retention improvement
}

\author{
Aman Tiwari *, Anjana Bharadwaj \\ RKDF College of Pharmacy, SRK University, Hoshangabad road, Misrod, Bhopal - 462026(MP) India
}

Received: 13 June 2020

Revised: 10 July 2020

Accepted: 5 August 2020

\begin{abstract}
Objective: The current study was projected to prepare a losartan potassium gastroretentive drug delivery system (GRDDS) of floating tablets was planned to enhance the gastric residence time, thus prolong the drug release. Material and methods: Effervescent floating matrix tablets of losartan potassium were prepared by direct compression technique using polymers like HPMC k4m, guar gum, and sodium bicarbonate, with lubricants magnesium stearate and talc. In the present study, sodium bicarbonate was incorporated as a gas generating agent. Total nine formulations were designed and evaluated for pre-compression parameters known as the angle of repose, bulk density, tapped density, Hausner's ratio, compressibility index, and post-compression parameters are uniformity of weight, hardness, and drug content percentage, and Fourier transform infrared spectroscopy (FTIR). Results: An in vitro dissolution study was carried out by using buffer $\mathrm{pH}$ 1.2. From in vitro dissolution studies, it has been found that an increase in polymer concentration diminishes the drug release profile. Conclusion: Tablets containing HPMC $\mathrm{K} 4 \mathrm{M}\left(20.00 \%\right.$, w/w), Ethyl cellulose $\left(8.0 \%\right.$, w/w) and $\mathrm{NaHCO}_{3}(10 \%$, w/w) (formula F9) showed satisfactory results with respect to floating lag time, total floating duration, swelling ability, and controlled drug release rates.
\end{abstract}

Keywords: Losartan potassium, HPMC K4M, guar gum, and direct compression technique, floating drug delivery systems (FDDS)

\section{Introduction}

Oral route is the most extensively used routes of the drug administration because of its obvious advantages of drug administration; improve patient compliance, and convenience. But conventional preparation is usually administered two or three times a day, which can lead to large fluctuation in drug plasma concentration and side effects on human body (Streubel et al., 2006).

Various approaches have been hypothesized to control the residence of drug delivery system (DDS) in the upper part of the gastrointestinal tract (GIT) such as the incorporation of passage delaying food agents, ion exchange resins, raft system, high-density DDS, floating drug delivery systems (FDDS), swelling or expandable DDS and mucoadhesive DDS (Nayak et al., 2010; Kothari and Manish, 2013).

\section{*Address for Corresponding Author:}

Aman Tiwari

RKDF College of Pharmacy, SRK University, Hoshangabad road, Misrod, Bhopal - 462026(MP) India

Email:taman7308@gmail.com
Floating drug delivery system (FDDS) is designed to prolong the residence time of the dosage form within the GI tract. It is the formulation of drug and gel forming hydrocolloids meant to remain buoyant on stomach contents. This not only prolong GI residence time but also does so in an area of GI tract that would maximize drug reaching its absorption site in solution form being ready for absorption. Drug dissolution and release from the tablet floating in gastrointestinal fluids occur at the stomach under fairly controlled condition. The retentive characteristics of the dosage forms in gastric content are most significant for drugs (Shah et al., 2017).

Losartan potassium is a potent, highly specific angiotensin II type 1(AT 1) receptor antagonist with antihypertensive activity. It is readily absorbed from the gastro intestinal tract with oral bioavailability of about $33 \%$ and a plasma half-life ranging from 1.5 to 2.5 hour (Goldsmith et al., 1978). Floating matrix tablets of losartan potassium were developed to prolong gastric residence time, leading to an increase in drug bioavailability.

DOI: https://doi.org/10.31024/apj.2020.5.4.3

2456-1436/Copyright (C) 2020, N.S. Memorial Scientific Research and Education Society. This is an open access article under the CC BYNC-ND license (http://creativecommons.org/licenses/by-nc-nd/4.0/). 


\section{Material and methods}

\section{Materials}

Losartan potassium was provided as a kind gift from Cadila Pharma, Ahemdabad, India. and guar gum were procured from Oxford Chemicals, Delhi. HPMC k15m are obtained from NR chemicals limited, Mumbai. Talc, sodium bicarbonateand magnesium stearate was procured from SD Fine Chem. Ltd, Mumbai, India. The all other reagents were used having an analytical grade.

\section{Preparation of losartan potassium floating tablets}

All the required ingredients sufficient for 20 tablets were weighed accurately and thoroughly mixed after passing through the sieve no. 22 in order to attain uniformity. Initially, required an amount of the active ingredient, i.e., losartan potassium and the polymer (guar gum /HPMC $\mathrm{k} 4 \mathrm{~m} / \mathrm{a}$ combination of these polymers) were calculated accurately and were mixed thoroughly with each other. Later on, an accurate amount of the effervescent agent $\mathrm{NaHCO}_{3}$ was added to the powder and mixed individually. Then the diluent, i.e., mannitol was mixed uniformly with the blend (Audumbar and Ritesh 2017; Ahmed et al., 2013).

Magnesium stearate and talc were then mixed with the tablet mixture as a lubricant. Tablets containing losartan potassium equivalent to $138.5 \mathrm{mg}$ were compressed by using the 10.0- millimeter diameter, spherical tablet punches on a 16 station rotary compression machine at the hardness of 5 to $6 \mathrm{~kg} / \mathrm{cm} 2$ The composition of all formulations was given in table 1 (Radhika et al., 2017).

Evaluation parameters for pre-compression of losartan potassium granules

\section{Determination of bulk density and tapped density}

A quantity of $5 \mathrm{~g}$ of the powder (W) from each formula was introduced into a $25 \mathrm{ml}$ measuring cylinder. After the initial volume was observed, the cylinder was allowed to fall under its own weight onto a hard surface from the height of $2.5 \mathrm{~cm}$ at $2 \mathrm{Sec}$ intervals. The tapping was continued until no further change in volume was noted. The bulk density, and tapped density were calculated using the following formulas:

Bulk density $=\mathrm{W} / \mathrm{V}_{\mathrm{O}}$

Tapped density $=\mathrm{W} / \mathrm{V}_{\mathrm{f}}$

Where, $\mathrm{W}=$ weight of the powder $\mathrm{V}_{\mathrm{O}}=$ initial volume

$\mathrm{V}_{\mathrm{F}}=$ final volume

\section{Angle of repose}

The flow characteristics are measured by angle of repose. Improper flow of powder is due to frictional forces between the particles. These frictional forces are quantified by angle of repose.

Angle of repose is defined as the maximum angle possible between the surface of a pile of the powder and the horizontal plane.

$\tan \Theta=\mathrm{h} / \mathrm{r}$

$\Theta=\tan ^{-1} \mathrm{~h} / \mathrm{r}$

Where $h=$ height of pile

$\mathrm{r}=$ radius of the base of the pile $\Theta=$ angle of repose

All the prepared Sustained release tablets were evaluated for following official and unofficial parameters.

\section{Compressibility index}

From the values of bulk and tapped densities a secondary method for determining powder flow is Carr's index. The powder arch potency or bridge strength and stability of the powder were directly measured by the percentage compressibility. Each formulation's Carr's index was calculated by the below-given equation (Manojkumar et al., 2015).

$$
\text { Carr's index }=\frac{\rho t-\rho b}{\rho t} \times 100
$$

Table 1. Formulation composition of losartan potassium

\begin{tabular}{|c|c|c|c|c|c|c|c|c|}
\hline Ingredients & F1 & F2 & F3 & F4 & F5 & F6 & F7 & F8 \\
\hline Losartan potassium & 50 & 50 & 50 & 50 & 50 & 50 & 50 & 50 \\
\hline Guar Gum & - & - & - & - & - & 120 & 100 & 80 \\
\hline Sodium Bicarbonate & 44 & 44 & 44 & 50 & 60 & 50 & 50 & 50 \\
\hline Citric Acid & 20 & 20 & 20 & 24 & 24 & 24 & 24 & 24 \\
\hline Lactose & 30 & 20 & 10 & 20 & 10 & 10 & 10 & 10 \\
\hline Magnesium stearate & 2 & 2 & 2 & 2 & 2 & 2 & 2 & 2 \\
\hline Talc & 4 & 4 & 4 & 4 & 4 & 4 & 4 & 4 \\
\hline Total & 450 & 450 & 450 & 450 & 450 & 450 & 450 & 450 \\
\hline
\end{tabular}


Where,

$\rho \mathrm{t}=$ tapped density $(\mathrm{kg} / \mathrm{m} 3)$,

$\rho b=$ bulk density $(\mathrm{kg} / \mathrm{m} 3)$

\section{Hausner's ratio}

Hausner's ratio is calculated by tapped density versus bulk density.

Hausner's ratio $=($ Tapped Density $) /($ Bulk Density $)$

\section{Uniformity of drug content}

In the formulation, the drug content was checked the dose uniformity. Randomly 10 tablets were selected individually and powered. The randomly selected powdered individual tablets were placed in a $100 \mathrm{ml}$ volumetric flask containing $\mathrm{pH} 1.2$ buffer solution and left undisturbed overnight. The drug content was determined after suitable dilutions by U. V-spectrophotometer at $234 \mathrm{~nm}$ against blank (Garg et al., 2019; Bharat et al. 2017).

\section{Evaluation parameters for post-compression}

\section{Thickness}

Twenty tablets were randomly selected from each batch and there thickness and diameter was measured by using digital vernier caliper.

\section{Friability}

Twenty tablets were weighed and placed in the Electrolab friabilator and apparatus was rotated at $25 \mathrm{rpm}$ for 4 minutes. After revolutions the tablets were dedusted and weighed again. The percentage friability was measured using the formula,

$\% \mathrm{~F}=\{1-(\mathrm{Wt} / \mathrm{W})\} \mathbf{x 1 0 0}$

Where, $\% \mathrm{~F}=$ friability in percentage, $\mathrm{W}=$ Initial weight of tablet, $\mathrm{Wt}=$ weight of tablets after revolution

\section{Tablet hardness}

The crushing strength $\mathrm{Kg} / \mathrm{cm} 2$ of prepared tablets was determined for 10 tablets of each batch by using Monsanto tablet hardness tester. The average hardness and standard deviation was determined.

\section{Results and discussion}

\section{Pre-compression parameters of losartan potassium granules}

The bulk density of various powder mixed blends prepared with different Polymer was measured by graduated cylinder. The bulk density was found in the range 0.427 $0.441 \mathrm{gm} / \mathrm{cm}^{3}$.

The Tapped density of various powder mixed blends prepared with different Polymer was measured by using measuring cylinder. The tapped density was found in the range $0.477-0.518 \mathrm{gm} / \mathrm{cm}^{3}$.

The Compressibility index of various powder mixed blends, prepared with different Polymer, using bulk density and tapped density data, compressibility index was calculated. It was found in the range 7.50-16.00\%.

The Hausner ratio of various powder mixed blends, prepared with different superdisintegrants, it is calculated by using bulk density and tapped density data. It was found in the range of 1.15-1.53.

Porosity of tablets was evaluated by using true density and bulk density data of tablets. It was found in the range $14-35 \%$.

The Angle of repose of various powder mixed blends, prepared with different Polymer, was measured by cylinder method. Angle of repose was found in the range $27.02^{\circ}$ $44.10^{0}$ The good Flow ability of powder blend was also evidenced with angle of repose which is indicated a good Flow ability. The results are given in table 2 .

\section{Post-compression parameters}

The thickness of the tablets was found in the range $4.2 \mathrm{~mm}-$ $4.3 \mathrm{~mm}$. Uniform thickness was obtained due to uniform die fill. Hardness of the tablets was found in the range 3.-3.5

Table 2. Pre-compression parameters

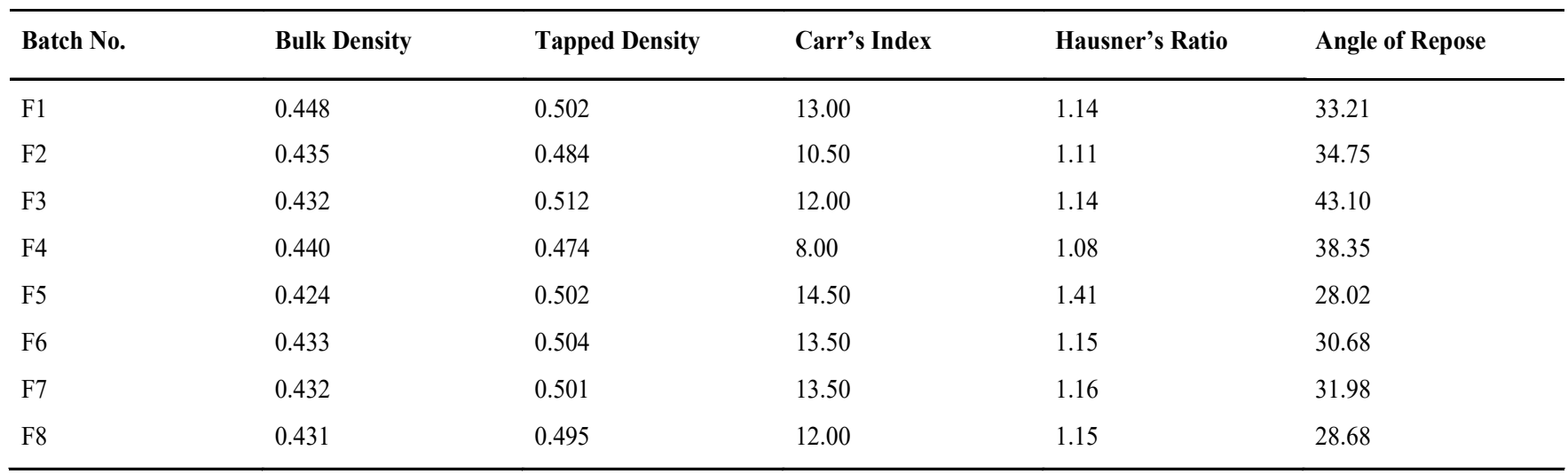


Table 3. Post-compression parameters

\begin{tabular}{lllll}
\hline Batch No. & \% Wt. Variation & Thickness & Hardness & Friability \\
\hline F1 & 1.15 & 4.20 & 3.6 & 0.32 \\
F2 & 1.37 & 4.25 & 3.5 & 0.24 \\
F3 & 4.28 & 3.0 & 0.28 \\
F4 & 1.20 & 4.30 & 3.4 & 0.35 \\
F5 & 1.17 & 4.24 & 3.2 & 0.20 \\
F6 & 1.32 & 4.25 & 3.1 & 0.38 \\
F7 & 1.23 & 4.30 & 3.3 & 0.40 \\
F8 & 1.18 & 4.25 & 3.5 & 0.20 \\
\hline
\end{tabular}

Table 4. In vitro drug release kinetic studies of different formulations

\begin{tabular}{lllllllll}
\hline Formulation & $\mathbf{0}$ & $\mathbf{1}$ & $\mathbf{2}$ & $\mathbf{4}$ & $\mathbf{6}$ & $\mathbf{8}$ & $\mathbf{1 0}$ & $\mathbf{1 2}$ \\
\hline F1 & 0.0 & 10.31 & 21.94 & 31.77 & 59.73 & 70.41 & 86.32 & 98.83 \\
F2 & 0.0 & 9.73 & 23.36 & 39.34 & 62.53 & 74.85 & 89.13 & 99.85 \\
F3 & 0.0 & 10.55 & 20.53 & 36.74 & 60.30 & 72.93 & 87.44 & 97.01 \\
F4 & 0.0 & 7.37 & 18.95 & 28.38 & 49.94 & 68.13 & 82.84 & 98.44 \\
F5 & 0.0 & 10.84 & 18.63 & 38.42 & 60.72 & 70.66 & 88.51 & 99.97 \\
F6 & 0.0 & 6.36 & 16.31 & 27.58 & 43.94 & 59.35 & 78.33 & 92.21 \\
F7 & 0.0 & 10.88 & 19.25 & 36.46 & 58.51 & 66.83 & 78.93 & 94.37 \\
F8 & 0.0 & 8.62 & 17.68 & 29.83 & 40.75 & 65.21 & 81.63 & 96.11 \\
\hline
\end{tabular}

Table 5. Content uniformity of Losartan Potassium

\begin{tabular}{lll}
\hline Formulation & Drug Content (\%) & \% RSD \\
\hline F1 & 100.08 & 1.67 \\
F2 & 100.24 & 2.22 \\
F3 & 100.23 & 1.12 \\
F4 & 97.84 & 1.78 \\
F5 & 99.90 & 3.35 \\
F6 & 98.38 & 3.85 \\
F7 & 99.48 & 1.11 \\
F8 & 101.64 & 1.61 \\
\hline
\end{tabular}

$\mathrm{kg} / \mathrm{cm} 2$. Uniform hardness was obtained due to equal compression force.

Tablets were evaluated by using Eletrolab Friabilator and friability of tablets was observed in acceptable range 0.19-0.83 (Less than 1\%).

\section{Conclusions}

The present work showed that promising controlled-release floating matrix tablets of Losartan Potassium were successfully formulated by effervescent technique. Tablets containing HPMC K4M (20.00\%, w/w), Ethyl cellulose (8.0\%, w/w) and $\mathrm{NaHCO}_{3}$
$(10 \%, w / w)$ (formula F9) showed satisfactory results with respect to floating lag time, total floating duration, swelling ability, and controlled drug release rates. Concentration and viscosity of polymer showed directly proportional relationship with swelling characteristics of tablet. As viscosity and concentration of polymers increased, release rate of drug was retarded.

\section{Acknowledgment}

Authors would like to thank management of SRK University, Bhopal for providing necessary lab facility to carry out the research work.

\section{Conflict of interests}

No conflict

\section{References}

Ahmed AA, Wedad KA, Al-saady FA. 2017. Formulation and evaluation of prochlorperazine maleate sustained floating release tablet. International Journal of Pharmacy and Pharmaceutical Sciences, 9:89-98.

Audumbar DM, Ritesh SB. 2017. Development and evaluation of gastroretentive floating tablets of a quinapril $\mathrm{HCL}$ by direct compression technique. International Journal of Pharmacy and Pharmaceutical 
Sciences, 9:35-46.

Bharat WT, Umesh TJ, Shruti GP, Vijay RP. 2017. Formulation and in vitro evaluation of floating tablets of cefpodoxime proxetil. International Journal of Current Pharmaceutical Research, 9:18-22.

Garg A, Garg S, Sahu NK, Yadav AK. 2019. Heparin appended ADH-anionic polysaccharide nanoparticles for site-specific delivery of usnic acid. International Journal of Pharmaceutics, 557:238-53.

Goldsmith JA, Randall N, Ross SD. 1978. On methods of expressing dissolution rate data. Journal of Pharmacy and Pharmacology, 30:347-349.

Kothari AH, Manish J. 2013. Gastroretentive drug delivery system and its approaches: a review. International Journal of Pharmaceutical Research and Development 4:7-18.

Manojkumar SP, Vidyasagar G, Patil VB. 2015. Formulation, optimization and evaluation of floating tablets clarithromycin. International Journal of Pharmacy and Pharmaceutical Sciences, 7:320-6.

Nayak AK, Malakar J, Sen KK. 2010. Gastroretentive drug delivery technologies: current approaches and future potential. Indian Journal of Pharmaceutical Education and Research, 1:1-10.

Radhika PR, Nishala N, Kiruthika M, Iswarya S. 2017. Design and evaluation of intragastric buoyant tablets of venlafaxine hydrochloride. Asian Journal of Pharmaceutical and Clinical Research, 10:166-70.

Shah HP, Prajapati ST, Patel CN. 2017. Gastroretentive drug delivery systems: from conception to commercial success. Journal of Critical Review, 4:10-21.

Streubel A, Siepmann J, Bodmeier R. 2006. Drug delivery to the upper small intestine window using gastro-retentive technologies. Current Opinion of Pharmacology, 6:501-8. 